\title{
UMA ANÁLISE DE REFERENCIAIS TEÓRICOS SOBRE A ESTRUTURA DO ARGUMENTO PARA ESTUDOS DE ARGUMENTACุÃO NO ENSINO DE CIÊNCIAS
}

Lúcia Helena Sasseron*

Anna Maria Pessoa de Carvalho**

RESUMO: A partir de um breve panorama de pesquisas que usam a argumentação como ferramenta de análise para as discussões estabelecidas em sala de aula de Ciências, mencionamos os pressupostos teóricos que fundamentam tais estudos e a importância dos mesmos para a compreensão do processo de construção do conhecimento. Limites e possibilidades dos referenciais utilizados nestas pesquisas despertam deste breve panorama e, a partir do exposto, apresentamos nossas críticas e fundamentamos nossa proposta alternativa para o estudo da argumentação, em que seja considerado, além da estrutura e da qualidade do produto final, o processo de argumentação e de interações múltiplas e contínuas que promovem a construção do argumento.

Palavras-chave: Argumentação, Ensino de Ciências, Metodologia de Pesquisa.

\section{AN ANALYSIS OF THEORETICAL FRAMEWORKS ABOUT ARGUMENT STRUCTURE FOR ARGUMENTATION STUDIES IN SCIENCE EDUCATION}

ABSTRACT: From a brief overview of research studies using argumentation as an analysis tool of science discussions in classrooms, we examine the theoretical assumptions that underlie such studies and their importance for understanding the process of building up scientific knowledge. Limits and possibilities of the frameworks used in these studies emerged from this brief overview. Then, we present our criticisms and build our alternative proposal for the study of argumentation where, in addition to the structure and quality of the final product, the argumentation process and the multiple and continued interactions that promote argument construction are also considered.

Keywords: Argumentation, Science Education, Research Methodology.

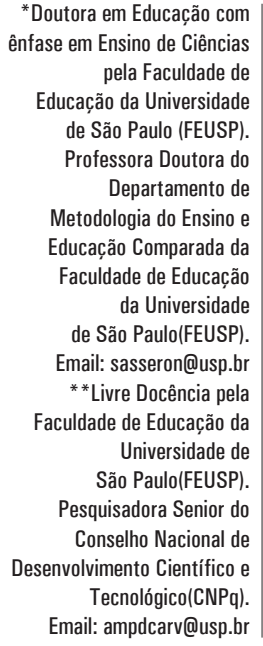




\section{A ARGUMENTAC̣̃̃O COMO UMA DAS PRINCIPAIS CARACTERÍSTICAS DA CIÊNCIA E DO ENSINO DE CIÊNCIA}

Uma das principais características do processo de construção das Ciências é a linguagem argumentativa.

Pesquisadores como Lemke (1997) apontam para a importância de considerar as singularidades da linguagem científica. No seu livro "Aprender a hablar ciencia", o autor compara a aprendizagem de um idioma estrangeiro com a aprendizagem de conteúdos de Ciências, afirmando que o conhecimento de um grande rol de sinônimos e definições de palavras e termos técnicos não são suficientes para que se saiba utilizar as palavras. Para ele, ao falar um idioma qualquer, ou ao falar ciência, é preciso que o locutor saiba combinar os significados de diversos termos e saiba perceber que esses significados podem variar em contextos diferentes.

As definições tentam transmitir o sentido do significado das palavras, mas para falar e entender, para ler e escrever, é necessário encontrar o significado de frases e orações completas, não de palavras isoladas. (1997, p.28, tradução nossa)

Por meio dessas idéias, Lemke propõe que, ao apresentar um conceito, os professores forneçam uma variedade de sinônimos às palavras usadas como forma de garantir mais flexibilidade aos significados. Ao mesmo tempo, é preciso que os alunos conheçam aquilo a que Lemke chama "relações de significado" entre as palavras, pois será no processo de relações que os estudantes construirão entendimento sobre uma dada noção, e, assim, terão aumentadas as possibilidades de compreender a que tal noção se refere dentro da cultura científica.

O processo de argumentação foi estudado do ponto de vista antropológico por Latour e Woolgar (1997/1979) ${ }^{1}$ e Latour (2000/1997) que mostraram que a linguagem argumentativa está presente tanto nos laboratórios, durante a construção dos fatos científicos, quanto nos congressos, durante as apresentações dos trabalhos, e principalmente nos artigos publicados pelos cientistas.

Segundo esses autores, é através da argumentação, realizada tanto em ambientes formais (artigos e palestras) como informais (conversas no ambiente de laboratório), que os cientistas convencem uns aos outros sobre a importância de seus trabalhos, a verdade do que dizem e a necessidade de investimentos no financiamento de seus projetos (Latour e Woolgar, op. cit.).

"A capacidade de persuasão é tal que eles conseguem convencer os outros,(...) porque estão seguindo uma orientação coerente de interpretação dos dados.(...) São tão convincentes que, no contexto de seu laboratório, épossivel esquecer a dimensão material do laboratório, das bancadas e a influência do passado, para consagrar-se exclusivamente aos 'fatos' postos em evidência." (Latour e Woolgar, p. 68)

Essa mesma dimensão argumentativa é buscada atualmente para o ensino de Ciências. Podemos mostrar este fato estudando as diretrizes, por exemplo, 
do projeto PISA. Este é o Projeto que procura avaliar o ensino de Ciências em diversos países e cujas diretrizes são acompanhadas também pelo Ministério de Educação brasileiro e refletidas nas provas nacionais como o ENEM e o SARESP. O Projeto PISA define assim a competência científica a ser avaliada:

"a capacidade de empregar o conbecimento cientifico para identificar perguntas e extrair conclusões baseadas em provas com fim de compreender e poder tomar decisões sobre o mundo natural e os câmbios que a atividade bumana produr neste" (OCDE / INECSE, 2004 p. 125)

E, especificamente no capítulo sobre as Ciências, é estabelecida como destreza importante:

"a capacidade de extrair conclusões apropriadas a partir de feitos e dados recebidos, de criticar os argumentos de outros com base em fatos e de distinguir entre uma mera opinião e uma afirmação sustentada porfatos." (op. cit. p. 123).

As avaliações - internacional e nacional - estão sinalizando para a busca de uma aprendizagem mais direcionada à forma de raciocinar em ciências e não como uma simples aquisição de conceitos. $\mathrm{E}$ a forma característica do raciocínio científico é aquela em que os enunciados, conclusões, hipóteses ou teorias não constituem meras opiniões, mas devem estar sustentadas em provas, dados empíricos ou respaldo de natureza teórica. Segundo Jiménez-Aleixandre e Diaz de Bustamante (2003):

Por argumentação entende-se a capacidade de relacionar dados e conclusões, de avaliar enunciados teóricos à luz dos dados empiricos ou procedentes de outras fontes. (p.360, tradução nossa, ênfase no original)

Assim, estudar o processo de argumentação - como desenvolvê-lo em sala de aula e como analisá-lo - passa ser um objetivo importante no planejamento do ensino, na formação de novos professores e, consequentemente, nas pesquisas nesse campo de investigação.

Neste artigo propomo-nos a estudar dois referenciais teóricos conhecidos nas pesquisas sobre argumentação da área de Ensino de Ciências, com o objetivo de compreender quais as contribuições e os limites dessas teorias para o estudo da construção de argumentos em situações de ensino e aprendizagem.

Para cumprir tal objetivo, discutiremos os referenciais teóricos e, com base nessas propostas, analisaremos episódios de uma aula de ciências ocorrida no Ensino Fundamental 1 (alunos com idades entre 9 e 10 anos).

\section{ESTUDOS SOBRE A ARGUMENTACฺ̃̃}

Em trabalho de 2005, que analisa o debate de questões sócio-científicas em sala de aula, Jiménez-Aleixandre propõe a argumentação, nesses casos, como 
a justificação do conhecimento científico ${ }^{2}$. Sendo essa justificação a forma com que os cientistas sustentam com provas, dados empíricos ou respaldo teórico seus enunciados, hipóteses e conclusões, procuramos os referenciais teóricos que nos permitissem entender como os cientistas constroem seus argumentos.

Em uma revisão extensa sobre os fundamentos metodológicos que envolvem o estudo da argumentação, Erduran (2008) afirma que a metodologia tem sido uma das grandes preocupações entre os pesquisadores dessa área e, tendo em vista os referenciais teóricos sobre a argumentação, registra problemas relacionados a critérios de validação das análises.

A grande maioria dos trabalhos revisados por Erduran (op.cit.) discute e apresenta o padrão de argumento proposto por Toulmin $\left(1958 / 2006^{3}\right)$ como referência principal para o estudo dos argumentos surgidos em situações de ensino e de aprendizagem. Erduran (op.cit.), então, aponta algumas das maneiras mais usuais pelas quais as ideias de Toulmin vêm sendo usadas nas pesquisas em ensino de Ciências e, dentre elas, destaca a necessidade de adaptações ao padrão originalmente proposto por diferentes pesquisadores, visando atender particularidades e peculiaridades da linguagem científica, bem como as interações estabelecidas em situações de aprendizagem sobre Ciências.

Conforme mencionamos anteriormente, tornar aceitas as ideias científicas exige a apresentação cuidadosa da relação entre observações, dados, evidências e conclusões. Entre as adaptações do TAP mencionadas por Erduran (op. cit.), aquela que mais recebe atenção diz respeito aos elementos W (garantia) e B (apoio): distingui-las nas argumentações sobre ciências mostra-se como uma difícil tarefa e, nesse sentido, adota-se a justificativa como sendo a intersecção entre estes dois elementos (Zohar e Nemet, 2002, Erduran et al, 2004, Jiménez-Aleixandre, 2004). É importante destacar que grande parte desses trabalhos pesquisa situações de ensino cujo foco são discussões sócio-científicas, ou seja, situações que, por sua característica intrínseca, já podem favorecer o aparecimento de posições antagônicas e/ou controversas, sendo necessário o uso de justificativas para tornar o argumento passível de aceitação.

No presente artigo, vamos trabalhar com dois autores que, no nosso entender, se complementam: Anton E. Lawson e Stephen S. Toulmin. Ambos desenvolveram propostas que nos permitem estudar a estrutura dos argumentos.

Lawson é um zoólogo com doutorado em História da Ciência e Ensino de Ciências; ele analisou textos históricos de grandes nomes da ciência em que eram relatadas as situações ao longo de um estudo, até a proposição de uma nova idéia. A partir dessas pesquisas, Lawson $(2000,2002)$ propôs que os cientistas fizeram uso do raciocínio hipotético dedutivo ao longo de suas investigações.

Toulmin, filósofo e educador, fez estudos no campo da retórica, com o objetivo de analisar argumentos retóricos. No livro "Os usos do argu2 Mmento" (1958/2006), Toulmin baseia-se na prática jurídica para a proposição da estrutura de um argumento.

Escolhemos apresentar os trabalhos de Lawson, pois este autor vai pro- 
curar, nos originais dos grandes cientistas, pistas da estrutura de seus raciocínios, isto é, vai procurar justamente como estes cientistas justificam suas hipóteses, seus dados empíricos para chegar às suas conclusões. E escolhemos o trabalho de Toulmin não apenas por ser o referencial teórico mais usado na área de Didática das Ciências em estudos sobre argumentação em sala de aula, mas também porque ele nos oferece um retrato muito claro do que foi discutido ao longo de uma aula. E, em nossa percepção, tendo claro o fim, é possível refazer o caminho na busca de compreender o que houve ali e que permitiu o final tal qual se obteve.

\section{Os trabalhos de Lawson}

Anton Lawson parte da hipótese de que a estrutura de pensamento dos pesquisadores que trazem grandes contribuições para o desenvolvimento das ciências obedece a um padrão comum, e propõe a seguinte questão: "poderia o raciocínio hipotético-dedutivo estar presente em todas as importantes descobertas cientificas?" (Lawson, 2002, p. 20, tradução nossa). Passa então a estudar os artigos de pesquisadores como Galileu, Alvarez, Alcock, em que eles descrevem situações diversas de suas investigações.

Em artigo de 2002, Lawson realiza uma introspecção do pensamento utilizado por Galileu Galilei a partir dos relatórios publicados no livro "Sideral Messenger". Como esses relatórios são apresentados em ordem cronológica, revelou-se uma grande oportunidade de estudar os aspectos chave do pensamento que guiou a descoberta científica das luas de Júpiter. Nesse artigo, Lawson propõe que o raciocínio hipotético-dedutivo conferiu base para a construção das idéias propostas pelo italiano Galileu.

Em outro artigo, Lawson (2004) apresenta a pesquisa de Walter Alvarez (1970-1990) sobre a causa de extinção maciça dos dinossauros há 65 milhões de anos. Alvarez descreveu o seu estudo em um livro intitulado "T. rex and the Crater of Doom", sendo esta obra bastante detalhada nos termos dos pensamentos do cientista, pois aborda cronologicamente diversas etapas do raciocínio utilizado. Assim como havia demonstrado no artigo anterior, no caso de Galileu, a partir dos dados descritos por Alvarez, Lawson mostra o raciocínio hipotético-dedutivo utilizado para cercear as idéias construídas.

Lawson (2000) também utiliza a pesquisa de Alcock, publicada em 1996, sob o título "Provisional Rejection of Three Alternative Hypotheses on the Maintenance of a Size Dichotomy in Males of Dawson's Burrowing Bee", na qual ele relata aspectos de sua investigação que contribuem para a compreensão de como ocorre a investigação.

Nesses três trabalhos, Lawson propõe o raciocínio hipotético-dedutivo como meio pelo qual as ideias foram organizadas. Locatelli (2006) sistematizou a proposta de Lawson da seguinte forma:

"A estrutura tem seu início com o termo "Se...", diretamente ligado às hipóteses (uma proposição); o termo "E..." diz respeito ao acréscimo de condições de base (um teste); o termo "Então..." é relativo aos resultados esperados (às conseqüências esperadas); o termo "E..." ou "Mas..." aos resultados e conseqüências reais e verdadeiras. O termo "E..." deve ser utilizado caso os resultados obtidos combinem com os esperados e o termo 
"Mas...", caso haja um desequilíbrio nos resultados; desta forma, o ciclo reinicia-se com outras hipóteses e, finalmente, o termo "Portanto..." introduz a conclusão a que se chega". (2006, p. 27)

A mesma estrutura pode ser representada pelo diagrama abaixo:

Figura 1: Padrão proposto por Lawson (2004).

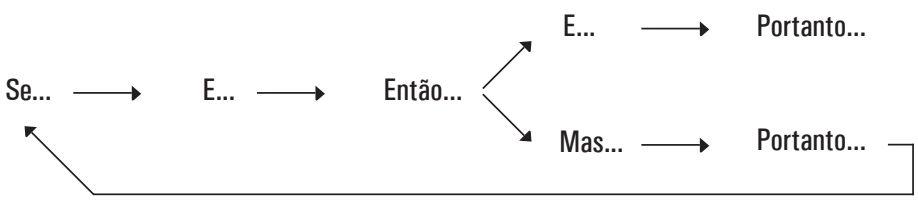

Segundo essa estrutura, Lawson propõe que esses padrões da razão científica têm sido usados para responder uma grande quantidade de questões científicas e que muitas das construções científicas são de natureza hipotético-dedutiva, pois as idéias envolvidas nos processos mentais de tais investigações evoluem seguindo esse padrão de representação na aquisição do conhecimento.

Com base nos trabalhos de Lawson, procuramos estudar a construção de ideias por alunos do Ensino Fundamental em atividades investigativas sobre tópicos da Física, quando eles resolviam problemas, em grupos pequenos, e discutiam os dados e resultados com a turma toda (Locatelli e Carvalho, 2007). Esse instrumento de análise se mostrou muito fértil, pois pudemos estudar e caracterizar as falas dos alunos. Encontramos essa mesma estrutura sendo desenvolvida durante toda a aula: inicialmente o 'se, então' quando os alunos descreviam o que fizeram, até que em suas últimas participações, quando buscavam uma explicação para o fenômeno, aparecia com bastante frequência a estrutura 'se, então, portanto'.

\section{0 padrão de argumento proposto por Toulmin}

Partindo do pressuposto de que as ciências são um corpo de conhecimento construído por seres humanos envoltos em âmbitos sociais e culturais, Toulmin apresenta-nos a ideia de que as atividades explicativas refletem a maneira como os homens tentam explicar a natureza, não sendo, pois, tais explicações a natureza em si. Nesse sentido, ganha aval sua premissa de que as ciências estão em constante transformação e, portanto, a capacidade de gerar novas perguntas, de buscar explicações para determinadas situações, relacionar dados e evidências na procura por previsões são alguns dos movimentos que permitem a construção de ferramentas conceituais.

Isso ressalta a premissa para a qual devemos dar atenção, a de que Toulmin preocupa-se em especial com o modo como as ideias são construídas e, nesse sentido, dá ênfase ao fato de que "nossas crenças pessoais só têm expressão mediante o uso de conceitos comuns" (1977, p. 54, tradução nossa). E essa ideia é por ele reforçada quando apresenta o argumento de que, embora os pensamentos sejam individuais, existe uma herança linguística e conceitual coletiva.

No livro "Os Usos dos Argumentos" (2006, originalmente publicado 
em 1958), Toulmin preocupou-se em estabelecer uma interpretação estrutural da argumentação, a fim de perceber de que modo sua validade ou invalidade está relacionada dentro do argumento. Seu objetivo era mostrar que nem todos os argumentos podem ser enquadrados na forma "das premissas às conclusões". Para tanto, partiu da questão: "O que, então, está envolvido no processo de estabelecer conclusões mediante a produção de argumentos?” (2006, p.139). Em resposta a essa pergunta, Toulmin apresenta os elementos constitutivos básicos da argumentação e as relações existentes entre eles.

O autor parte da ideia de que uma asserção feita defende uma alegação. Os fatos que apoiam esta alegação são os dados (D) e são os fundamentos com os quais se constroi o suporte à conclusão (C) que se busca apresentar. Deste modo, podemos perceber que a "asserção original apóia-se em fatos apresentados que se relacionem a ela." (2006, p.140).

Como somente os dados não são suficientes para validar a conclusão, são necessárias informações adicionais a fim de relacionar D e C. Essas informações adicionais são, para Toulmin, as garantias (W) e nos permitem entender de que modo o argumento passou dos dados à conclusão.

Segundo Toulmin, as garantias podem ser regras ou princípios, mas não devem ser informações novas. São, portanto, afirmações gerais, hipotéticas; e são as garantias que nos permitem fazer o caminho dos dados às conclusões.

O autor ainda se preocupa com casos em que dado, garantia e conclusão não são suficientes para tornar o argumento aceito. Nesses casos, um qualificador modal (Q) surge e se torna a "força que a garantia empresta à conclusão" (2006, p.153). Segundo Toulmin, o qualificador modal é, via de regra, um advérbio que dá aval à conclusão obtida. No viés oposto, as condições de exceção ou refutação (R) fazem com que a garantia perca força e conteste as suposições por ela criadas.

O último elemento apresentado por Toulmin é aquele que dá aval e autoridade às garantias: é o apoio (B) que traz mais força à garantia do argumento.

A partir disso, Toulmin apresenta-nos o padrão que confere uma forma ao argumento:

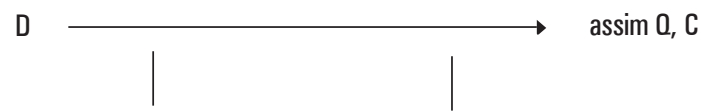

já que $\mathrm{W} \quad$ a menos que $\mathrm{R}$

por conta de B

As ideias de Toulmin têm sido muito utilizadas nas pesquisas sobre ensino e aprendizagem das ciências e seu padrão de argumento (conhecido na literatura mundial como TAP, Toulmin Argument Pattern) é usado amplamente para o estudo dos argumentos produzidos em aulas de Ciências. Isso fica mais 
evidente ainda em trabalhos que versam sobre a importância de se considerar a argumentação em aulas de ciências como meio de formar alunos que tenham uma visão mais adequada das ciências e do modo como as mesmas constroem e estruturam suas ideias (Driver e Newton, 1997, Capecchi e Carvalho, 2000, Jiménez-Aleixandre, Bugallo-Rodríguez e Duschl, 2000, Vieira e Nascimento, 2009, Locatelli e Carvalho, 2007).

\section{Alguns limites da aplicabilidade do padrão de argumento de Toulmin apontadas por investigadores do Ensino de Ciências}

Dentre as ferramentas teórico-metodológicas utilizadas nas pesquisas em ensino e aprendizagem de Ciências, o modelo de padrão de argumento proposto por Toulmin parece ser o mais popular, possivelmente porque apresenta um caráter prescritivo definindo, o que é e o que não é um argumento (Erduran et al, 2006).

Embora muito utilizado, vários pesquisadores fazem críticas ao modelo, mostrando restrições e propondo complementações para melhor adequação à realidade do ensino e da aprendizagem.

Driver et al (2000) apontam limites para a utilização do modelo de Toulmin. O primeiro desses limites é que o padrão não considera o contexto da construção da argumentação, o que é muito importante na sala de aula. Mostram também que partes da argumentação, como a garantia, muitas vezes não são explicitadas nos discursos, mas estão implícitas. Outro ponto apontado pelos autores é que o fluxo natural da conversação não necessariamente se desenvolve em sequência, sendo então difícil a caracterização da argumentação em sala de aula, e mostram também que, principalmente no ensino das ciências, nem tudo é feito oralmente, usam-se muitas linguagens semióticas: gestos são apontados; materiais são manipulados, ilustrações e gráficos complementam as comunicações.

Zohar e Nemet (2002), ao estudar situações de sala de aula com temáticas sócio-científicas, identificaram a dificuldade de enquadrar as falas de alunos e professores no TAP. Estudando a mesma temática, Erduran et al (2004) depararam-se com a mesma dificuldade, principalmente para encontrar os elementos $\mathbf{W}$ e $\mathbf{B}$ do TAP, e, para contornar o problema, propuseram a fusão desses dois elementos em um único: a justificativa.

Outro exemplo de dificuldade em identificar o TAP em sala de aula pode ser encontrado no trabalho de Maloney e Simon (2006): estudando o desenvolvimento das interações discursivas em aulas de ciências, o objetivo das autoras era entender os processos de colaboração estabelecidos entre os estudantes para construção de argumentos. Propuseram, então, a elaboração de mapas de discussão para a descrição de como essas interações ocorriam e, então, posterior análise dos argumentos que pudessem ter sido construídos nessas oportunidades.

Jiménez Aleixandre et al (1998), quando da utilização do modelo de Toulmin para a análise da argumentação dos alunos em aulas de ciências propuseram primeiramente uma ampliação, ou uma maior caracterização do que Toulmin em seu modelo define como dado. Os autores criaram duas categorias específicas para 
identificação da procedência do dado. Nomearam de dado fornecido (DF) aquele que chega para os alunos, em sala de aula, através do professor, livro-texto, roteiro do experimento; por dado obtido (DO) os autores se referem àqueles advindos de situações experimentais. Os dados obtidos (DO), por sua vez, podem ser subclassificados em dado empírico (DE), como no caso dos dados que procedem de uma experiência no laboratório, ou dado hipotético $(\mathrm{DH})$, quando eles são uma construção mental para uma investigação que se tem em plano.

Para estudar as interações em sala de aula, Jiménez-Aleixandre et al (2000) caracterizaram aspectos das argumentações dos alunos que não podiam ser representados usando somente o padrão de Toulmin. Eles definiram então as operações epistêmicas - dedução; causalidade; definição; classificação; apelo a analogias, a exemplos, etc; consistência e plausibilidade - e as utilizaram para analisar as argumentações dos alunos juntamente com a análise por meio do padrão de Toulmin.

Em trabalhos cujo objetivo era entender como ocorria o processo de Alfabetização Científica entre alunos do Ensino Fundamental (Sasseron, 2008, Sasseron e Carvalho, 2008), também não foi possível analisar as argumentações ocorridas em sala de aula somente com o padrão de Toulmin. Assim, a proposta estabeleceu um paralelo entre as ideias apresentadas por Toulmin para a constituição de seu padrão de argumento e os indicadores da Alfabetização Cientifica: seriar informações; organizar informações; classificar informações; raciocínio lógico; raciocínio proporcional; levantamento e teste de hipótese; justificativa; previsão e explicação. Com esses dois referenciais de análise, as autoras deram conta de estudar todos os discursos argumentativos (orais e escritos) dos alunos, que ocorreram durante as aulas.

Em complementação a essas ideias, Sasseron e Carvalho (2011) propõe a possibilidade de surgir um ciclo argumentativo em discussões de sala de aula na construção de noções sobre temas de e sobre ciências. Essa proposta analisa tanto o aparecimento de indicadores de AC nessas aulas quanto a construção de argumentos por professor e alunos. Em linhas gerais, o ciclo argumentativo teria início com a retomada de ideias já discutidas, para que haja o trabalho com informações já existentes, e seria seguido pelo reconhecimento e delimitação de variáveis; nesses momentos, elementos do TAP como $\mathbf{B}, \mathbf{W}$ e $\mathbf{R}$ podem ser trazidos à tona. Em seguida, por meio do cruzamento de informações, relações passam a ser estabelecidas entre ideias e surgem as oportunidades para que sejam explicitados os elementos $\mathbf{D}$ e $\mathbf{C}$ do TAP.

Nascimento e Vieira (2008) exprimem bem o problema da utilização do padrão de Toulmin na pesquisa em ensino de ciências:

“(...) as limitacõoes apontadas do padrão são mais fruto da sua utilização fora do campo que Toulmin inicialmente lhe deu ao concebê-lo do que propriamente devido à lacunas que o filósofo tenha deixado dentro do seu campo de concepşão" (p.17).

Os autores ainda concluem seu artigo apontando a necessidade de criar e aperfeiçoar as adaptações do padrão de Toulmin para se utilizado como referencial analítico nas pesquisas sobre argumentação nas aulas de ciências. 


\section{Os significados dos elementos de um argumento no ensino}

Tendo em mente os cuidados que precisam ser tomados quando da adoção do padrão de argumento de Toulmin para estudar e analisar as situações de sala de aula de ciências, queremos, inicialmente, discutir a necessidade de dar atenção aos sentidos atribuídos aos termos que denotam cada um dos elementos presentes no padrão de Toulmin.

Antes de quaisquer comentários, é preciso deixar explícito que Toulmin se preocupou em estudar o quão coeso e coerente pode ser um argumento. Em sala de aula, estamos interessados também na coesão e na coerência de um argumento, mas o processo de ensino e de aprendizagem é mais do que somente a apresentação de um argumento: a sua construção e todos os aspectos nela envolvidos são muito importantes de serem considerados, ou seja, na sala de aula, o estudo do processo da argumentação é tão importante quanto o estudo da qualidade do argumento oferecido.

A ideia de dado, tal qual expressa no padrão de Toulmin, difere do que seriam os dados empíricos ou hipotéticos que entram em cena na construção de modelos de explicação nas ciências. Em Toulmin, os dados referem-se a alegações que se pretende apresentar e aparecem sempre ligados à conclusão a que se pretende chegar. Esse par tem, portanto, papel de tese que será defendida na presença dos interlocutores.

$\mathrm{Na}$ sala de aula, um dado pode se configurar em uma informação que já se possui, seja advinda da experimentação ocorrida em algum momento das aulas ou uma ideia que os estudantes já possuem de suas vivências extra-escolares. Consiste, pois, em uma evidência que será trabalhada nas discussões. Encontrar coerência entre aquilo que se possui de informação inicial e as novas situações colocadas em pauta nas intervenções de alunos e professor torna-se o meio que permite o estabelecimento da argumentação em sala de aula.

Assim também a conclusão, em processos de sala de aula, difere da conclusão tal qual vemos no padrão de argumento de Toulmin. Nas situações escolares, ela será entendida como as relações estabelecidas envolvendo a constatação das informações já existentes e que permitem se referir a certas regularidades daquele contexto estudado. E aqui reside um grande problema do uso do padrão de Toulmin para analisar o ensino e a aprendizagem de ciências.

Ainda pensando nos significados dos elementos do padrão de Toulmin, vamos comentar agora as garantias e os refutadores. Estes são termos que, em sala de aula, na construção de noções científicas, aparecem quando alunos e professor lançam-se em discussões sobre os fatores condicionantes do fenômeno em questão. Nesse sentido, explorar as possibilidades das ideias trazidas em uma discussão é fundamental para a construção do conhecimento, uma vez que é nesses momentos que se começa a considerar quais as variáveis realmente atreladas ao fenômeno investigado, além de que se torna possível perceber como elas se relacionam.

A explicitação das garantias e dos refutadores, conforme propõe o pró- 
prio Toulmin, são afirmações hipotéticas que ali aparecem para conceder apoio à tese defendida. Mas é preciso considerar que, muito provavelmente, eles terão advindo do trabalho com informações que se conseguiu organizar ao longo das discussões. Eles podem se tornar ainda mais fortes dentro do argumento, caso façam referência direta ao apoio, ou seja, às informações que já se possuía, aos conhecimentos básicos sobre aquele assunto.

É importante ressaltar mais uma vez esses termos já que, ao longo de uma sequência de aulas, pode ser possível proporcionar a alteração do status de uma informação, passando, por exemplo, do papel de tese para o papel de apoio ao argumento que se apresenta. Partindo desse pressuposto, reforçamos nossa colocação acima explicitada de que o tempo para a construção de um padrão de argumento em sala de aula difere do tempo para a construção de um argumento jurídico e, similarmente, a explicitação de um e de outro terão especificidades tais que, pensando na sala de aula, merecem ser cuidadas.

\section{COM O FOCO NO REFERENCIAL DE ANÁLISE: UM EXEMPLO DE ANÁLISE DE SITUAÇÃO DE ENSINO E APRENDIZAGEM}

Queremos agora considerar algumas nuances importantes do raciocínio hipotético-dedutivo proposto por Lawson e também do padrão de argumento de Toulmin.

Na proposição de Lawson, podemos identificar claramente o levantamento e o teste de hipóteses ao longo de uma investigação, contudo, o trabalho com as informações pode ocorrer por meio de inúmeros ciclos "se-então" até que se identifiquem as variáveis relevantes para uma dada situação e, assim, pares de associação de ideias seriam estabelecidos.

No que tange às ideias que sustentam a proposição de padrão de argumento de Toulmin, conforme já mencionado, o autor recorre ao exercício jurídico de apresentação de pontos de vistas. Assim, o par $D, C$ de seu padrão apresenta-se como uma tese a ser defendida; tese esta que ganha maiores coerência e coesão quando são apresentados os outros elementos constituintes do padrão original.

Neste momento, temos então que parar para refletir sobre a sala de aula de ciências: quais são as possibilidades do uso do padrão de argumento de Toulmin e das ideias de raciocínio hipotético-dedutivo, proposto por Lawson, para a análise das argumentações construídas em aula? Quais são os limites que temos que respeitar para, a partir da estrutura do argumento, entender a qualidade do que é enunciado?

\section{A construção social do argumento em sala de aula}

Agora voltamos nossa atenção ao aspecto da construção do argumento e das relações que conectam cada um dos elementos na explicitação do padrão de argumento de Toulmin e/ou da estrutura hipotética-dedutiva proposta por Lawson.

Já mencionamos anteriormente que Toulmin era um estudioso da retórica; assim sendo, torna-se clara sua intenção explícita de, ao defender uma premis- 
sa, trazer elementos para a proposição, de tal modo que ela possa se tornar o mais convincente possível. Nesse contexto, uma tese é defendida ressaltando de onde surgiram as premissas, quais as conclusões possíveis a partir delas, além das garantias que sustentam tal alegação e dos contra-argumentos que apontam contestações para aquela linha de construção e que, assim como as garantias, podem trazer aval positivo à tese que se tem em mente afirmar. Apresenta-se, pois, o argumento.

Já na sala de aula, um argumento está em construção. As conversas, as discussões, a explicitação e a tomada de consciência dos resultados advindos de atividades ou de outras fontes de informações, as divergências e as confluências em torno de um mesmo tema, todas estas são algumas das formas por meio das quais as ideias são colocadas em cena e consideradas na sala de aula. São esstes diferentes momentos de expressão que levam à percepção de como se conectam as diversas informações e que permitem o agrupamento lógico das pequenas peças das falas na elaboração de um argumento que denota a compreensão do fenômeno debatido seja construído. A estrutura proposta por Lawson pode nos trazer evidências de que o processo está em desenvolvimento.

Neste momento do texto, apresentamos um episódio de ensino ocorrido em uma sala de aula de $4^{\circ}$. ano do Ensino Fundamental. Este episódio deve nos permitir a análise dos referenciais teóricos de Toulmin e Lawson, pois, ao término da aula, argumentos foram construídos. A atividade central da aula a ser analisada é a discussão do texto "Mantendo navios na água". O objetivo central desta leitura é levar os alunos a travar conhecimento do que seja o lastro, sua finalidade, como e quando ele é utilizado, tipos de lastro e a forma mais comum utilizada hoje em dia, e, para tanto, o texto relembra a necessidade de que a distribuição de carga seja uniforme em uma embarcação de modo a garantir sua estabilidade.

A aula teve início com a retomada, feita pela professora, das ideias discutidas na aula anterior: semelhanças e diferenças entre embarcações. Assim como naquela oportunidade, nesta aula a professora busca chamar a atenção dos alunos para o fato de que o formato da embarcação está relacionado à função que ela tem. Além disso, procura fazer com que os alunos reconheçam a necessidade de distribuição uniforme de massa em uma embarcação como condição para sua flutuação.

Em meio à leitura do texto, a professora apresenta o lastro e, com auxílio de uma figura ilustrativa, apresenta aos alunos os tanques de lastro que existem em uma embarcação. Posto este cenário, propõe o seguinte problema: 


\begin{tabular}{|c|c|c|}
\hline TURNO & & $\begin{array}{c}\text { AÇ̃̃ES DA } \\
\text { PROFESSORA E } \\
\text { INDICADORES DE AC }\end{array}$ \\
\hline 106 & $\begin{array}{l}\text { Professora: (...) Ele tirou a água lá do outro porto, encheu } \\
\text { o lastro e viajou. Aí chegou na cidade lá que ele precisa } \\
\text { carregar, que ele ia pegar a mercadoria, aí ele vai jogar a } \\
\text { água de lastro fora porque ele vai encher o tanque de carga } \\
\text { dele. Então ele vai encher o tanque dele de carga com as } \\
\text { mercadorias, com os contêineres, com as coisas que ele vai } \\
\text { transportar, e vai jogar fora a água de lastro. E aí ele vai } \\
\text { continuar a viagem dele com a carga cheia e a água de lastro } \\
\text { vazia porque ele já não precisa de todo esse peso para ter } \\
\text { estabilidade. (pausa) Perguntas. (pausa) Não?! Fala, Luciano. }\end{array}$ & $\begin{array}{l}\text { Apresentação de novas } \\
\text { informações culmina } \\
\text { com a explicitação de } \\
\text { uma nova situação }\end{array}$ \\
\hline 107 & $\begin{array}{l}\text { Luciano: É por causa que se o navio for muito leve, e... se a } \\
\text { água bater muito forte nele, ele pode tombar, aí a água deixa } \\
\text { ele mais pesado, aí ele aguenta mais. }\end{array}$ & $\begin{array}{l}\text { Levantamento de hipótese, } \\
\text { raciocínio lógico, previsão, } \\
\text { justificativa }\end{array}$ \\
\hline 108 & $\begin{array}{l}\text { Professora: (concordando) Ele fica mais estável. É isso } \\
\text { mesmo. Se ele tá muito leve e tem uma tempestade ou um } \\
\text { vento muito forte, corre o risco dele ficar, né?, tombando e a } \\
\text { depender do vento, da força que bate nele, ele pode correr o } \\
\text { risco de tombar. Com a água de lastro, faz ele ficar firme. E } \\
\text { vocês perceberam que os tanques de lastro eles são iguaizi- } \\
\text { nhos tanto de um lado quanto de outro? Por que que precisa } \\
\text { ser igualzinho tanto de um lado quanto de outro? }\end{array}$ & $\begin{array}{l}\text { Proposiçãa de uma nova } \\
\text { situação-problema }\end{array}$ \\
\hline 109 & $\begin{array}{l}\text { Daniel: Por causa que se tem uma parte com mais água que a } \\
\text { outra, com mais carga que a outra, ele corre o risco de tombar. }\end{array}$ & $\begin{array}{l}\text { Raciocínio lógico, explicação, } \\
\text { justificativa, previsão }\end{array}$ \\
\hline 110 & Professora: (concordando) Fala, Marina. & \\
\hline 111 & $\begin{array}{l}\text { Marina: Tem que ter água dos dois lados do barco porque se } \\
\text { colocar muita água de um lado e pouca do outro, ele pode } \\
\text { tombar assim pro lado (faz gestos indicando o desequilíbrio). }\end{array}$ & $\begin{array}{l}\text { Levantamento de hipótese, } \\
\text { raciocínio lógico, previsão, } \\
\text { justificativa, explicação }\end{array}$ \\
\hline 112 & Professora: (concordando) Ele pode tombar. & \\
\hline
\end{tabular}

Neste breve trecho, a partir da apresentação de novas informações, a professora realiza a proposição de uma nova situação-problema. Luciano, o primeiro aluno a buscar uma solução para a proposta da professora, apresenta uma ideia sobre o que deverá ocorrer: a força da água chocando-se com uma embarcação que não está muito estável pode levá-la ao tombamento. A fala de Luciano pode ser transposta ${ }^{4}$ para a estrutura de Lawson:

É por causa que se o navio for muito leve, e... se a água bater muito forte nele, [então] ele pode tombar, [então] aí a água deixa ele mais pesado, aí [portanto] ele aguenta mais.

Ainda que a situação por ele descrita possa se tornar real, e considerando que Luciano apresenta uma previsão que supostamente decorria do cenário descrito, a fala do aluno estabelece uma associação entre ideias: a massa inserida em 
uma embarcação e sua estabilidade.

Imediatamente a professora dá aval positivo à proposta de Luciano e menciona o papel do lastro nesta situação. Além disso, refere-se a uma figura apresentada aos alunos onde uma embarcação é retratada com seus tanques de lastro dispostos de maneira uniforme. Uma ação importante da professora deve ser destacada neste momento: com o ensejo surgido pela fala do aluno, a professora identifica as variáveis (massa e espaço) e propõe uma nova situação-problema aos alunos: considerar o porquê da necessidade de haver os tanques uniformemente distribuídos ao longo da embarcação.

Em resposta a esse novo problema proposto pela professora, Daniel apresenta ideias muito semelhantes àquelas propostas por Luciano, ou seja, a necessidade de estabilidade para evitar que a embarcação tombe; mas é preciso notar que a proposição de Daniel traz um acréscimo ao que foi dito pelo colega: ele agora menciona a necessidade de distribuição de carga como forma de garantir a estabilidade mencionada por Luciano. A fala de Daniel também pode ser lida dentro da estruturada proposta por Lawson:

Por causa que se tem uma parte com mais água que a outra, com mais carga que a outra, [então] ele corre o risco de tombar.

A estrutura a que chegamos para a fala de Daniel é muito semelhante àquela que construímos para a fala de Luciano; mas suas falas são muito diferentes uma da outra, pois Daniel estabelece uma relação causal entre as duas informações: ao pautar a distribuição da massa como sendo a possibilidade de haver mais ou menos carga em um dado espaço, Daniel deixa clara a relação construída entre as duas variáveis e, da análise delas, propõe uma previsão para a situação.

Na sequência, a fala de Marina une as duas colocações e apresenta uma ideia completa sobre a situação investigada: assumindo as hipóteses apresentadas pelos colegas, ela associa carga de uma embarcação e sua distribuição e, assim como Daniel, explicita relação entre variáveis massa e espaço para distribuição e, assim, explica o porquê de ser necessário haver uma carga mínima em uma embarcação, além da necessidade de que esta esteja distribuída, e, com isso, chega a estabelecer uma previsão associada àquela situação. A fala de Marina pode ser examinada sob a ótica da estrutura de Lawson:

[portanto] Tem que ter água dos dois lados do barco porque se colocar muita água de um lado e pouca do outro, [então] ele pode tombar assim pro lado.

Com este pequeno episódio, ilustramos nossa proposição de que a construção de um argumento trata-se de um processo complexo e não-linear, envolvendo a participação de diferentes atores da sala de aula. Esta afirmação ganha aval quando identificamos que, logo no início do trecho, a professora propõe uma problema aos alunos e obtém uma resposta que, ainda que possa ser considera- 
da como ligada à temática debatida e estruturada em um raciocínio hipotético dedutivo (Lawson, 2002, 2000), explicita uma associação entre ideias e não uma relação entre variáveis. O papel da professora foi essencial: ao ressaltar as variáveis em questão e propor um novo problema, ela faz com que os alunos construam relações entre elas. Além disso, a complementação de ideias de um aluno para outro e o refinamento na explicitação das mesmas avaliza não apenas as boas ações desempenhadas pela professora neste processo como também torna clara a colaboração entre os estudantes.

\section{O ensino de Ciências precisa ir além das conclusões}

Ainda existe outro aspecto relacionado ao padrão de argumento de Toulmin e à estrutura hipotética-dedutiva de Lawson que precisa ser considerado quando utilizamos um ou outro para a análise dos argumentos explicitados em aulas de ciências: o papel da conclusão para esses referenciais e para a construção de uma noção científica na sala de aula.

Considerando a proposta de Toulmin, a conclusão tem o papel de termo final de uma proposição. Nesse sentido, ela é bastante específica e limitada àquele contexto da alegação que se propõe. Na proposta de Lawson, a conclusão poderia ser identificada pela explicitação do portanto.

Como mencionamos anteriormente, para a construção de um conceito científico em sala de aula, estabelecer uma conclusão não significa construir uma noção científica: tão importante quanto a conclusão é também a possibilidade de construir previsão sobre ações decorrentes do fenômeno estudado.

Em sala de aula, na construção de um argumento, esperamos que seja possível tecer relações que conectem as informações existentes com estruturas operatórias logicamente construídas. A intenção é de obter relações que possam ser estendidas para outros contextos e, portanto, gerar possibilidade de prever fenômenos e situações.

Defendemos então a necessidade de que o argumento não fique restrito a regularidades ocorridas em um evento particular, pois somente isso não é suficiente para a construção de significados científicos. Assim, é importante a possibilidade de construção de noções mais gerais.

$\mathrm{Na}$ situação abaixo, retratamos um episódio da mesma sequência de aulas anteriormente analisada. Agora, alunos e professora discutem relações entre presa e predador, após terem realizado um jogo sobre essa temática em aula e analisado os dados provenientes dele. 


\begin{tabular}{|c|c|c|}
\hline TURNO & & $\begin{array}{c}\text { AÇ̃̃ES DA } \\
\text { PROFESSORA E } \\
\text { INDICADORES DE AC }\end{array}$ \\
\hline 116 & $\begin{array}{l}\text { Professora: Não, vamos pensar na natureza agora, tá? Vamos } \\
\text { pensar na natureza. Um ambiente onde a gente tem tapitis, } \\
\text { onde a gente tem jaguatiricas e onde a gente tem plantas. Aqui } \\
\text { a pergunta tá pedindo pra gente pensar nas jaguatiricas, } 0 \\
\text { número que foi baixo. Se eu tenho pouca jaguatirica nesse am- } \\
\text { biente, o que que vai acontecer com a quantidade de tapitis? }\end{array}$ & Propõe um problema \\
\hline 117 & Luciano: Eles vão diminuir. & \\
\hline 118 & Professora: Mas eu tenho pouca jaguatirica. & \\
\hline 119 & Júnior: Vão aumentar. & \\
\hline 120 & $\begin{array}{l}\text { Professora: (concordando) Os tapitis vão aumentar, já } \\
\text { que o predador do tapiti tá em menor quantidade. }\end{array}$ & Sistematiza ideias \\
\hline 121 & Júnior: E ele come a planta e não é comido pela jaguatirica. & Explicação \\
\hline 122 & $\begin{array}{l}\text { Professora: (concordando) Come a planta e não é } \\
\text { comido pela jaguatirica. } 0 \text { que que vai acontecer } \\
\text { com o número das plantas nesse caso? }\end{array}$ & $\begin{array}{l}\text { Sistematiza ideias e } \\
\text { propõe um problema }\end{array}$ \\
\hline 123 & Luciano: Vai diminuir. & \\
\hline 124 & Professora: (concordando) Vai diminuir. Por que que vai diminuir? & \\
\hline 125 & $\begin{array}{l}\text { Luciano: Por causa que vai ter muito tapitis e eles } \\
\text { vão comer muitas plantas, aí vai diminuir bastante. }\end{array}$ & $\begin{array}{l}\text { Explicação, previsão, } \\
\text { raciocínio lógico }\end{array}$ \\
\hline 126 & $\begin{array}{l}\text { Professora: (concordando) Vai diminuir bastante. Agora va- } \\
\text { mos pensar diferente. Vamos pensar que a gente tem muita } \\
\text { jaguatirica nesse ambiente, o que que vai acontecer? }\end{array}$ & \\
\hline 127 & Luciano: Elas vão comer muitos tapitis, os tapitis vai diminuir. & $\begin{array}{l}\text { Explicação, previsão, } \\
\text { raciocínio lógico }\end{array}$ \\
\hline 128 & Júnior: Diminuir, e as jaguatiricas vai aumentar. & \\
\hline 129 & Professora: E o que que acontece com as plantas? & $\begin{array}{l}\text { Explicação, previsão, } \\
\text { raciocínio lógico }\end{array}$ \\
\hline 130 & $\begin{array}{l}\text { Júnior: Também vão aumentar porque } \\
\text { os tapitis não vão comer elas. }\end{array}$ & $\begin{array}{l}\text { Explicação, previsão, } \\
\text { raciocínio lógico }\end{array}$ \\
\hline
\end{tabular}

Neste episódio, a partir da sistematização de ideias apresentadas pelos alunos nos momentos aqui retratados ou em outros ocorridos nesta mesma aula, a professora propõe novas situações problemáticas aos alunos; e são esses pequenos problemas, colocados um após o outro, que permitem aos alunos explicitarem ideias sobre o que ocorrerá na relação entre presa e predador em diferentes situações.

Afirmações feitas pelos alunos no turnos 125, 127, 128 e 130 são bons exemplos; falas que, sozinhas, não podem ser transpostas para a estrutura de argumento proposta por Toulmin ou para a estrutura hipotética-dedutiva de Lawson, contudo são afirmações que explicam as situações problemáticas construídas pela 
professora e prenunciam comportamentos em decorrência da situação exposta. Ainda que isoladas, as informações de cada uma dessas falas auxiliam na construção de um visão mais ampla sobre as relações existentes entre presa e predador para o caso específico ilustrado pelo jogo.

Ao término dessa discussão, chegamos ao seguinte TAP:

Dado que "o número de indivíduos de uma espécie está relacionado às relações entre presa e predador" então "insuficiente número de presas pode levar à extinção dos predadores" já que "poucas presas levam ao decréscimo do número de predadores e muitos predadores levam ao decréscimo do número de presas".

Como dissemos, as falas selecionadas no episódio acima apresentado não podem ser transpostas diretamente para este TAP, mas foram elas que permitiram a construção de uma garantia como esta que é explicitada aqui: uma garantia de elementos co-dependentes.

Na continuação da discussão que ocorria no episódio acima, destacamos mais uma fala de aluno:

\begin{tabular}{c|c|c} 
TURNO & $\begin{array}{c}\text { AÇ̃̃ES DA } \\
\text { PROFESSORA E } \\
\text { INDICADORES DE AC }\end{array}$ \\
\hline 152 & $\begin{array}{c}\text { Luciano: É como se fosse um equilíbrio. As plantas vão ter } \\
\text { pouco, mas o deles vai ter muito. Aí se tiver pouca planta, vai } \\
\text { dar comida pra poucos tapitis. Os outros vão morrer e vão virar } \\
\text { plantas. Aí vai ter mais plantas, ai o tapiti vai comer. Aí as } \\
\text { jaguatiricas vão comer tapiti. É como se fosse um equilíbrio. }\end{array}$ & $\begin{array}{c}\text { Explicação, justificativa, } \\
\text { previsão, raciocínio lógico, } \\
\text { raciocínio proporcional }\end{array}$ \\
\hline
\end{tabular}

No padrão de argumento de Toulmin, a fala de Luciano pode ser organizada do seguinte modo:

O dado é apresentado quando ele diz que "As plantas vão ter pouco, mas o deles vai ter muito". Daqui, uma conclusão possível é que "Os outros vão morrer e vão virar plantas". Esta conclusão encontra respaldo na garantia expressa quando Luciano afirma: "se tiver pouca planta, vai dar comida para poucos tapitis".

Mas o mais interessante nesta manifestação de Luciano é que seu argumento não pára na conclusão: há idéias explicitadas que nos demonstram claramente a sua percepção de que aquela situação descrita pode ser estendida para outras situações desde que respeitadas as condições de contorno propostas. Isso fica evidente quando Luciano declara que aquele fenômeno "é como se fosse um equilíbrio", pois esta sua colocação permite as demais inferências ("Os outros vão morrer e vão virar plantas. Aí vai ter mais plantas, aí o tapiti vai comer. Aí as jaguatiricas vão comer tapiti”) que atuam como previsões de ocorrências a serem vislumbradas naquele contexto.

Para nós, fica então muito clara a necessidade de, ao estudar as diferentes argumentações em sala de aula, ir além de apenas entender qual a estrutura que regula a construção de um argumento: precisamos destinar atenção para o potencial de adequação daquele argumento para outras situações. 


\section{ALGUMAS CONCLUSÕES}

A estrutura hipotética-dedutiva proposta por Lawson pode nos fornecer algumas evidências de como as ideias estão sendo trabalhadas pelos alunos, no entanto, ela não nos permite distinguir claramente quando a conexão entre ideias é uma simples associação e quando se trata de uma relação causal entre variáveis. Desse modo, ainda que adequado para compreender a estrutura de raciocínio utilizada pelo interlocutor, ela não se mostra completamente satisfatória para o estudo da qualidade das ideias pronunciadas.

Deter-nos-emos, agora, um pouco mais, sobre o padrão de argumento de Toulmin, uma vez que, conforme já mencionado, ele vem sendo amplamente utilizado pelos pesquisadores de Didática das Ciências que analisam os processos discursivos em sala de aula. Nesse sentido, nossa atenção a ele já é importante pelo simples fato de que podemos ter com quem dialogar em busca de aprofundar estudos em desenvolvimento.

O TAP é uma ferramenta eficaz nos procedimentos de análise das argumentações no ensino de Ciências porque apresenta caráter prescritivo, enquadrando o que é um argumento e demarcando claramente daquilo que não é, quando caracteriza e descreve a função dos constituintes estruturais do argumento: dado (D), conclusão (C), garantia (W), qualificadores modais (Q), refutação (R) e o conhecimento básico (B) e definindo que um argumento para ser considerado como completo deve apresentar pelo menos dado, conclusão e justificativa.

Contudo, estas nossas breves análises deixam-nos evidências de que existem nuances na construção do argumento que precisam ser estudadas; e não é escopo do TAP estudar essas nuances. De todo modo, ao encontrar um argumento em sala de aula que se enquadre na estrutura proposta por Toulmin, temos evidência de que um dos objetivos da aula foi cumprido: construir explicações científicas coerentes; mas a outra vertente importante, a qualidade do argumento, não pode ser conferida por esse instrumento de análise.

Além de algumas considerações em relação ao estado em que se encontram as pesquisas sobre as argumentações como forma de promover ensino e aprendizagem mais significativos sobre as ciências, gostaríamos de mencionar aqui alguns possíveis desdobramentos que um estudo mais meticuloso das argumentações, levando em consideração os limites e as possibilidades do uso dos referenciais aqui discutidos, pode trazer para o trabalho docente.

Interessa-nos compreender de que modo o trabalho do professor, em aulas investigativas, pode promover e fomentar discussões mais ricas em sala de aula. Aqui não estamos nos referindo somente às habilidades de saber fazer perguntas e de saber ouvir seus alunos (Carvalho, 2007), estamos também mencionando a necessidade de se saber qual o tipo de pergunta que pode e deve ser feito em cada momento da aula. Assim, a compreensão de quando cada um dos elementos do padrão de Toulmin é apresentado nas discussões em sala de aula e do modo como os significados entre professor e alunos são negociados até se obter uma idéia que 
seja aceita por todos e que esteja em conformidade com o conhecimento científico em questão podem nos ajudar a compreender que tipo de pergunta é mais apropriada a cada momento da discussão.

Torna-se clara, portanto, a necessidade de alguns tipos básicos de questões que precisam ser estimuladas em sala de aula se desejamos que os alunos, orientados pelo professor, sejam capazes de construir argumentos que representem suas ideias em relação a dados fenômenos e situações: perguntas que façam os alunos recordar noções já existentes ou construir uma base com as novas informações adquiridas em determinada aula; perguntas que levem os alunos a discutir quais as variáveis que verdadeiramente influenciam no fenômeno investigado; questões que recorram à necessidade de se buscar correspondências entre essas variáveis; questões que façam com que se dê atenção às relações entre as variáveis que podem ser generalizáveis; perguntas que suscitem a necessidade de se considerar contra-exemplos das situações estudadas.

\section{NOTAS}

${ }^{1}$ Sempre que houver duas datas separadas pelo sinal / a primeira refere-se à publicação em português e a segunda à publicação original.

${ }^{2}$ A autora não aborda o conhecimento não científico neste seu trabalho e, por não fazer parte de seu escopo, a justificação que pode ser apresentada nestes casos não é por ela estudada.

${ }^{3}$ O livro foi originalmente publicado em 1958, mas, para nossos estudos, utilizamos a edição brasileira de 2006.

${ }^{4}$ Nesta adaptação, as palavras em negrito e itálico representam elementos da estrutura contidos na própria fala do aluno. Palavras em itálico dentro de colchetes representam elementos que inserimos no texto para demonstrar a construção.

\section{REFERÊNCIAS BIBLIOGRÁFICAS}

CAPECCHI, M.C.V.M e CARVALHO, A.M.P, “Argumentação em uma Aula de Conhecimento Físico com Crianças na Faixa de Oito a Dez Anos", Investigações em Ensino de Ciências, v.5, n.2, 171-189, 2000.

CARVALHO, A.M.P., Habilidades de professores para promover a enculturação científica, Contexto \& Educação, v.77, n.1, 2007.

DRIVER, R., NEWTON, P. e OSBORNE, J., Establishing the norms of scientific argumentation in classrooms. Science Education, v.84, n.3, 287-312, 2000.

DRIVER, R. e NEWTON, P., Establishing the Norms of Scientific Argumentation in Classrooms, ESERA Conference, Roma, 1997.

ERDURAN, S., "Methodological foundations in the study of argumentation in science classrooms". In ERDURAN, S. e JIMENEZ-ALEIXANDRE, M.P. (Eds.), Argumentation in Science Education: Perspectives from Classroom-Based Research. Dordrecht: Springer, 2007.

ERDURAN, S., SIMON, S., e OSBORNE, J., “TAPping into Argumentation: Developments in the use of Toulmin's Argument Pattern in Studying Science Discourse", Science Education, v.88, n.6, pp.915-933, 2004. 
JIMÉNEZ-ALEIXANDRE, M.P., A argumentação sobre questões sócio-científicas: processos de construção e justificação do conhecimento na aula, ATAS do ENPEC, Bauru, 2005.

JIMÉNEZ-ALEIXANDRE, M.P., BUGALLO-RODRÍGUEZ, A. e DUSCHL, R.A., "Doing the Lesson" or "Doing Science": Argument in High School Genetics", Science Education, v.84, 757-792, 20, 2000. JIMÉNEZ-ALEIXANDRE, M.P., e DÍAZ DE BUSTAMANTE, "Discurso de Aula y Argumentación en la Clase de Ciências: Cuestiones Teóricas y Metodológicas", Enseñanza de las Ciencias, v.21, n.3, 359-370, 2003.

LATOUR, B. Ciência em ação: como seguir cientistas e engenheiros sociedade afora. São Paulo: Editora da Unesp, 2000.

LATOUR, B. e WOOLGAR, S. A vida de laboratório: a produção de fatos científicos. Rio de Janeiro: Relume Dumará, 1997.

LAWSON A.E. How do humans acquire knowledge? And what does that imply about the nature of knowledge? Science \& Education, v.9, n.6, 577-598, 2000.

LAWSON A.E. T. rex, the crater of doom, and the nature of scientific discovery. Science \& Education, v.13, n.1, 155-177, 2004.

LAWSON A.E. What does Galileo's Discovery of Jupter's Moons Tell Us About the Process on Scientific Discovery? Science \& Education, v.11, n.1, 1-24, 2002.

LEMKE, J.L., Aprender a hablar Ciencia, Buenos Aires, Paidós, 1997.

LOCATELLI, R. J. Uma análise do raciocinio utilizado pelos alunos ao resolverem os problemas propostos nas atividades de conhecimento físico. Dissertação de Mestrado apresentada ao IF/FE-USP, São Paulo, 2006.

LOCATELLI, R. J. e CARVALHO, A.M.P. Uma análise do raciocínio utilizado pelos alunos ao resolverem os problemas propostos nas atividades de conhecimento físico, Revista Brasileira em Educaşão em Cièncias, v.7, n.3, 1-18, 2007.

NASCIMENTO, S.S. e VIEIRA, R.D. Contribuições e limites do padrão de argumento de Toulmin aplicado em situações argumentativas de sala de aula de ciências. Revista Brasileira de Pesquisa em Educaşão em Ciências, v.8 n.2, 1-21, 2008.

OCDE / INECSE (2004) Marcos teóricos de PIS A 2003. Conocimientos y destrezas en Matemáticas, Lectura, Ciencias y Solución de Problemas (tradução de The PIS A 2003 Assessment Framework: Mathematics, Reading, Science and Problem Solving Knowledge and Skills). Madrid: Instituto Nacional de Evaluación y Calidad del Sistema Educativo. Ministerio de Educación y Ciencia.

SASSERON, L.H., Alfabetização Cientifica no ensino Fundamental - Estrutura e Indicadores deste processo em sala de aula, tese apresentada à Faculdade de Educação da USP, 2008.

SASSERON, L.H. e CARVALHO, A.M.P. Almejando a alfabetização científica no ensino fundamental: a proposição e a procura de indicadores do processo. Investigações em Ensino de Ciências, v.13, n.3, 333-352, 2008. SASSERON, L.H. e CARVALHO, A.M.P., "Construindo argumentação na sala de aula: a presença do ciclo argumentativo, os indicadores de Alfabetização Científica e o padrão de Toulmin”. Ciência \& Educação, v.17, n.1, 2011.

MALONEY, J. e SIMON, S., "Mapping childrens discussion of evidence in science to assess collaboration and argumentation", International Journal of Science Education, v.28, n.15, 1817-1841, 2006.

TOULMIN, S.E., Os usos do argumento, São Paulo, Contraponto, 2006.

TOULMIN, S.E., La comprensión bumana - 1. El uso colectivo y la evolución de los conceptos, Alianza Editorial, Madrid, 1977.

VIEIRA, R.D. e NASCIMENTO, S.S., Uma proposta de critérios marcadores para identificação de situações argumentativas em salas de aula de Ciências, Caderno Brasileiro de Ensino de Física, v.26, n.1, 81-102, 2009. ZOHAR, A. e NEMET, F., Fostering students' knowledge and argumentation skills through dilemmas in human genetics, Journal of Research in Science Teaching, v. 25, n.5, 685-725, 2002.

Data de Recebimento: 06/10/2010

Data de Aprovação: 25/08/2011

Data da Versão Final: 20/09/2011 